\title{
A 4-year-old boy with ataxia and aphasia
}

\author{
Robert L. Myette MD MSc, Jenna Webber MD, Hannah Mikhail BSc, Kirk Leifso MD
}

Cite as: CMAJ 2020 May 25;192:E578-82. doi: 10.1503/cmaj.191279

See related articles at www.cmaj.ca/lookup/doi/10.1503/cmaj.191660 and www.cmaj.ca/lookup/doi/10.1503/cmaj.191194

A n otherwise healthy 4-year-old boy was brought to hospital in late December after 3 days of nasal congestion and 2 days of fever, vomiting, malaise, ataxia and aphasia. The patient had a medical history of clubfoot. He had not yet received his immunizations (4-6 yr) or the seasonal influenza vaccine. On arrival, his vital signs were normal, but he had truncal and gait ataxia. The remainder of his neurologic and physical examination was normal. There was no nuchal rigidity, no ankle clonus and the Babinski sign was negative.

\section{What diagnoses should be ruled out in this patient?}
a. Central nervous system infection
b. Brain neoplasm
c. Poisoning
d. Cerebrovascular accident
e. All of the above.

The answer is (e). Several conditions can cause acute ataxia and aphasia (Table 1). Initial biochemical and toxicologic workup showed a white blood cell count of 20 (normal range 4.7-13.5) $\times$ $10^{9}$ cells $/ L$, a neutrophil count of 18 (normal range $\left.1.5-8.50\right) \times$ $10^{9}$ cells/L and a lymphocyte count of 1.6 (normal range $1.0-$

\begin{tabular}{|c|c|c|}
\hline Condition & Ataxia & Aphasia \\
\hline Acute cerebellitis & + & \\
\hline Acute cerebellar ataxia (postinfectious) & + & \\
\hline Bacterial meningitis & + & \pm \\
\hline Mycoplasma pneumoniae pneumonia & + & \\
\hline \multicolumn{3}{|l|}{ Enterovirus encephalitis } \\
\hline HSV encephalitis & + & \\
\hline EBV encephalitis & + & \\
\hline Cerebellar tumour & + & \\
\hline Lyme disease (neuroborreliosis) & + & \pm \\
\hline
\end{tabular}

5.5) $\times 10^{9}$ cells/L. On presentation to hospital, the patient's highsensitivity C-reactive protein was 36.2 (normal $\leq 10$ ) $\mathrm{nmol} / \mathrm{L}$ ) with an erythrocyte sedimentation rate of 26 (normal $0-20$ ) $\mathrm{mm} / \mathrm{h}$.

Acute viral encephalitis can present with fever and neurologic deficits. We started intravenous acyclovir and ceftriaxone to provide empiric coverage for encephalitis caused by herpes simplex virus (HSV) and bacterial meningitis, respectively. Stroke, both hemorrhagic and ischemic, and brain tumours would be visible on imaging and were considered. We planned a magnetic resonance imaging (MRI) of the head, but shortly after admission the patient's mental status declined. He developed nystagmus, tremor, hyperreflexia with ankle clonus, a positive right-sided Babinski reflex and urinary incontinence. Seizure-like movements were noted, and he was given lorazepam.

\section{What is your next step?}
a. Urgent brain computed tomography (CT)
b. Lumbar puncture
c. Brain MRI
d. Electroencephalography
e. Observation

The answer is (a). An urgent CT scan was done to rule out intracranial hemorrhage or a space-occupying lesion as a cause of his acute neurologic deterioration. In our case, this was normal. A lumbar puncture is required to make a diagnosis of infectious meningitis or encephalitis, which we performed after the head CT. A sample of cerebrospinal fluid (CSF) was clear and colourless with a lymphocytic pleocytosis (Table 2). A bacterial culture of CSF showed no growth. Results from polymerase chain reaction (PCR) of CSF for HSV1, HSV2 and varicella zoster virus, enterovirus and parechovirus were negative (Table 2). We stopped treatment with acyclovir. His brain MRI showed a nonnecrotizing, nonhemorrhagic meningoencephalitis (Figure 1). Further investigations included electroencephalography, electrocardiography, echocardiography and abdominal ultrasonography, which were all normal. After his deterioration, pediatric infectious diseases was consulted. Upon questioning, his parents shared a photograph of a rash that had developed 4 months earlier (Figure 2). 


\begin{tabular}{|c|c|c|}
\hline Laboratory test & Result & $\begin{array}{l}\text { Reference } \\
\text { range }\end{array}$ \\
\hline CSF glucose, $\mathrm{mmol} / \mathrm{L}$ & 2.9 & $3.3-4.4$ \\
\hline CSF protein, g/L & 0.55 & $0.15-0.45$ \\
\hline CSF appearance & Clear/colourless & Clear/colourless \\
\hline Red blood cells, $\times 10^{6}$ cells $/ \mathrm{L}$ & $<1$ & $0-5$ \\
\hline White blood cells, $\times 10^{6}$ cells $/ \mathrm{L}$ & 39 & $0-7$ \\
\hline CSF neutrophil differential & $1 \%$ & NA \\
\hline CSF lymphocyte differential & $80 \%$ & NA \\
\hline CSF mono/macro differential & $19 \%$ & NA \\
\hline Bacterial culture & Negative & Negative \\
\hline PCR for HSV/VZV & Negative & Negative \\
\hline PCR for enterovirus RNA & Negative & Negative \\
\hline PCR for Borellia species & Negative & Negative \\
\hline
\end{tabular}

Note: $\mathrm{CSF}=$ cerebrospinal fluid, $\mathrm{HSV}=$ herpes simplex virus, $\mathrm{NA}=$ not applicable, $\mathrm{PCR}=$ polymerase chain reaction, $\mathrm{VZV}=$ varicella zoster virus.

\section{Based on the photograph, what is the diagnosis?}
a. Encephalitis associated with HSV
b. Pneumonia associated with Mycoplasma pneumoniae
c. Lyme neuroborreliosis
d. Encephalitis associated with Epstein-Barr virus (EBV)
e. Drug reaction

The answer is (c). The patient lived in southeastern Ontario in an area highly endemic for Lyme disease. Four months before presenting to the hospital, the patient was seen in an urgent care clinic for multiple disseminated erythematous patches that had appeared 5 days earlier. The lesions had appeared after 2 days of fever and vomiting. At the time, there was no history of headache, facial asymmetry, visual changes, weakness, palpitations, shortness of breath with exertion or joint involvement. He had played in a wooded area at a local farm, but there was no recollection of a tick bite. The fever and skin lesions were diagnosed as erythema multiforme, which resolved completely 1 month after they appeared. A drug eruption can cause erythema multiforme; however, our patient had no exposure to medication. Erythema multiforme lesions are usually no more than $1-2 \mathrm{~cm}$ in diameter, do not enlarge and often appear on the palms and soles, unlike in our patient. There were no respiratory symptoms to suggest pneumonia associated with M. pneumoniae.

Peripheral Lyme serology testing was reactive and included immunoglobulin G (IgG) and immunoglobulin M (IgM) immunoblots (Table 3). Polymerase chain reaction of CSF for Borrelia species was negative; however, this test has very low sensitivity, and therefore this result did not change our diagnosis. Unfortunately, there was not enough CSF to test for intrathecal anti-Borrelia antibody production. Serum serology testing was also reactive for Bartonella henselae IgG by immunoflorescence assay (titre of 1:256) and EBV IgM but nonreactive for EBV IgG. Ongoing exposure to cats at home and the tendency for Lyme disease to cause falsely reactive serology for other infections, such as EBV, explained this. Our patient's clinical picture was not consistent with meningoencephalitis associated with $B$. henselae. He was improving by the fifth day of ceftriaxone administered intravenously and back to baseline by the seventh day. Our patient completed his intravenous ceftriaxone course as an outpatient.

\section{Discussion}

Lyme disease is a tick-borne infection caused by Borrelia burgdorferi and transmitted in North America primarily by the deer tick Ixodes scapularis. Ixodes scapularis is well established in the Kingston, Frontenac, Lennox and Addington region in Ontario and at least
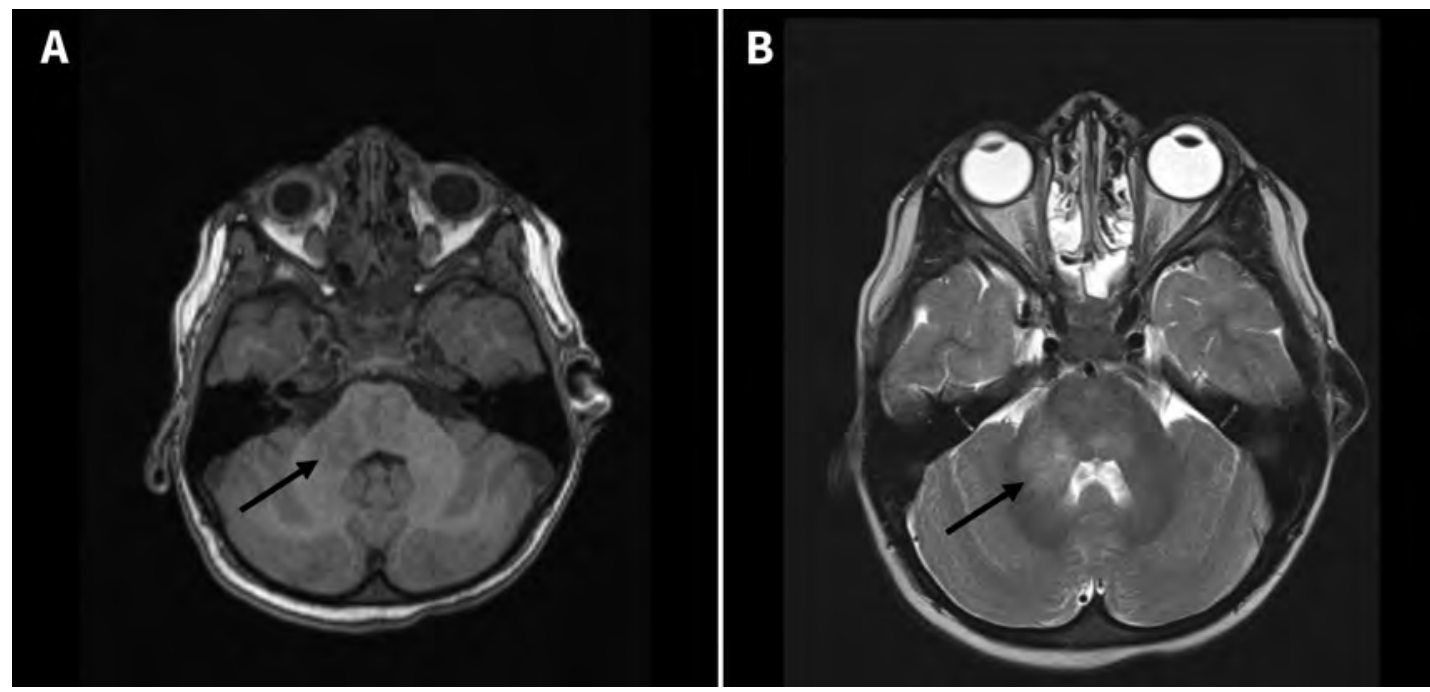

Figure 1: Magnetization-prepared rapid gradient-echo ( $T_{1}$-weighted; left view)and turbo spin-echo ( $T_{2}$-weighted; right view) magnetic resonance images showing multifocal asymmetric edema of the cortical, deep grey matter and white matter tracts, with no cranial nerve involvement (black arrows). 


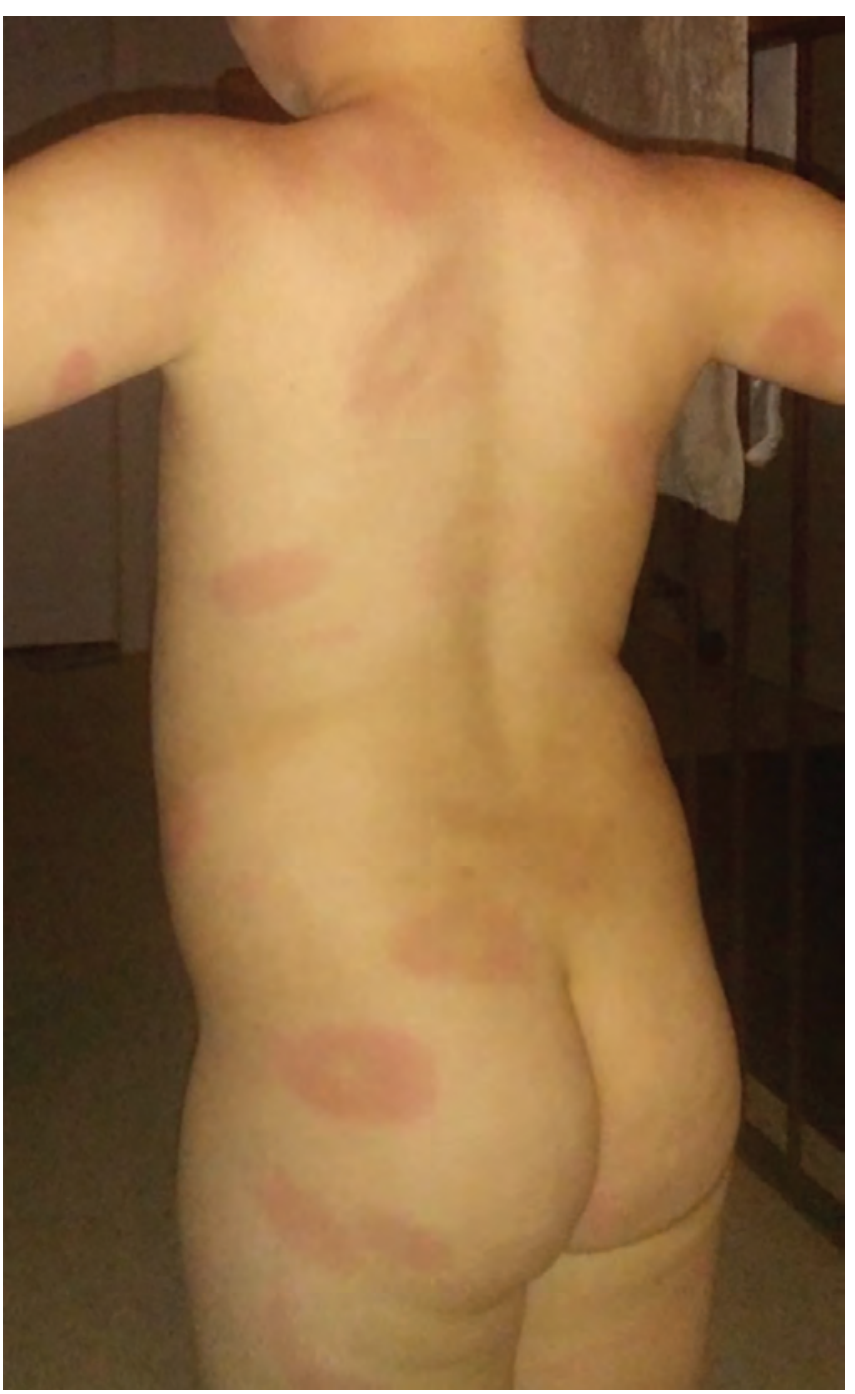

Figure 2: Disseminated erythema migrans initially misdiagnosed as erythema multiforme. Published with permission of the patient's parents.

$30 \%$ of this tick population carries Borrelia burgdorferi (Figure 3). In 2017 , this region reported an incidence of 96.3 cases of Lyme disease per 100000 population, whereas the overall incidence in the province of Ontario was 7.2 cases per 100000 population. ${ }^{1}$

Lyme disease manifests in 3 stages: early localized ( $\leq 30 \mathrm{~d}$ ), early disseminated (1-3 mo) and late disseminated disease ( $\geq 3 \mathrm{mo}$. ${ }^{2}$ Early localized disease is recognized by the presence of erythema migrans, a relatively asymptomatic, expanding, erythematous patch with or without central clearing. In North America, a minority of erythema migrans appear as the classical "bull'seye" lesion. Erythema migrans may be confused with other skin lesions, such as erythema multiforme, as seen in our patient. ${ }^{2}$

Early disseminated Lyme disease can present with multiple areas of erythema migrans, carditis and neuroborreliosis alone or in combination. ${ }^{2}$ Nonspecific symptoms such as fever, lymphadenopathy, headache, myalgia and arthralgias may also be present but are more common in the early localized and early disseminated stages. Late disseminated Lyme disease mainly manifests as arthritis. ${ }^{2,3}$ Neuroborreliosis may involve the peripheral nervous
Table 3: Results of microbiologic investigations in a 4-year-old boy with aphasia and ataxia

\begin{tabular}{|c|c|}
\hline Laboratory test & Result \\
\hline EBV EA IgG & Nonreactive \\
\hline EBV VCA IgG & Nonreactive \\
\hline EBV EBNA IgG & Nonreactive \\
\hline EBV VCA IgM & Reactive \\
\hline Measles IgG & Reactive \\
\hline Measles IgM & Nonreactive \\
\hline Mumps IgG & Nonreactive \\
\hline Mumps IgM & Nonreactive \\
\hline Urine RNA for mumps & Negative \\
\hline CMV IgG & Nonreactive \\
\hline CMV IgM & Nonreactive \\
\hline Bartonella IgG titre & $1: 256$ \\
\hline Lymphocytic choriomeningitis IgG & Nonreactive \\
\hline Lymphocytic choriomeningitis IgM & Nonreactive \\
\hline Lyme IgG/IgM EIA & Reactive \\
\hline Lyme IgM Western blot & Reactive \\
\hline Lyme IgG Western blot & Reactive \\
\hline \multicolumn{2}{|l|}{ Nasopharyngeal swab } \\
\hline Influenza A/B PCR & Negative \\
\hline Viral culture & Negative \\
\hline \multicolumn{2}{|l|}{ Stool culture } \\
\hline Bacterial culture & No growth \\
\hline Norovirus PCR & Positive \\
\hline Rotavirus ICT & Negative \\
\hline
\end{tabular}

Note: $\mathrm{CMV}=$ cytomegalovirus, $\mathrm{EA}=$ enzyme assay, $\mathrm{EBNA}=$ Epstein-Barr virus nuclear antigen, $E B V=$ Epstein $-B a r r$ virus, $E I A=$ enzyme immunoassay, $I C T=$ indirect Coombs test, IgG = immunoglobulin $\mathrm{G}$, IgM = immunoglobulin M, PCR = polymerase chain reaction, $\mathrm{VCA}=$ viral capsid antigen

system (facial nerve palsy), the central nervous system (CNS) as a lymphocytic meningitis or, uncommonly, both. ${ }^{4}$ Usually, brain parenchyma are not directly involved in CNS infection, ${ }^{5}$ and findings from MRI are usually in keeping with rhomboencephalitis. ${ }^{6}$ Late neuroborreliosis, particularly when it manifests as meningoencephalitis several months after initial infection, is uncommon. ${ }^{5}$ Acute cerebellar ataxia has been reported in childhood Lyme disease $;^{7}$ however, ataxia in children is more likely caused by viral infections or M. pneumoniae. ${ }^{8}$

A review of childhood neuroborreliosis in Sweden reported that the most common presenting features were headache $(61 \%)$, fatigue (60\%) and cranial nerve palsy (59\%). ${ }^{9}$ Most patients presented between July and September, whereas only $10 \%$ of patients presented in December. ${ }^{9}$ In a similar study in Denmark, less than $20 \%$ of children with Lyme disease who lived in an endemic area had presented in November or December. ${ }^{4}$ The most common signs and symptoms included radicular pain (66\%), cranial nerve palsy $(43 \%)$ and headache (28\%). Meningitis (2\%-4.9\%) and 


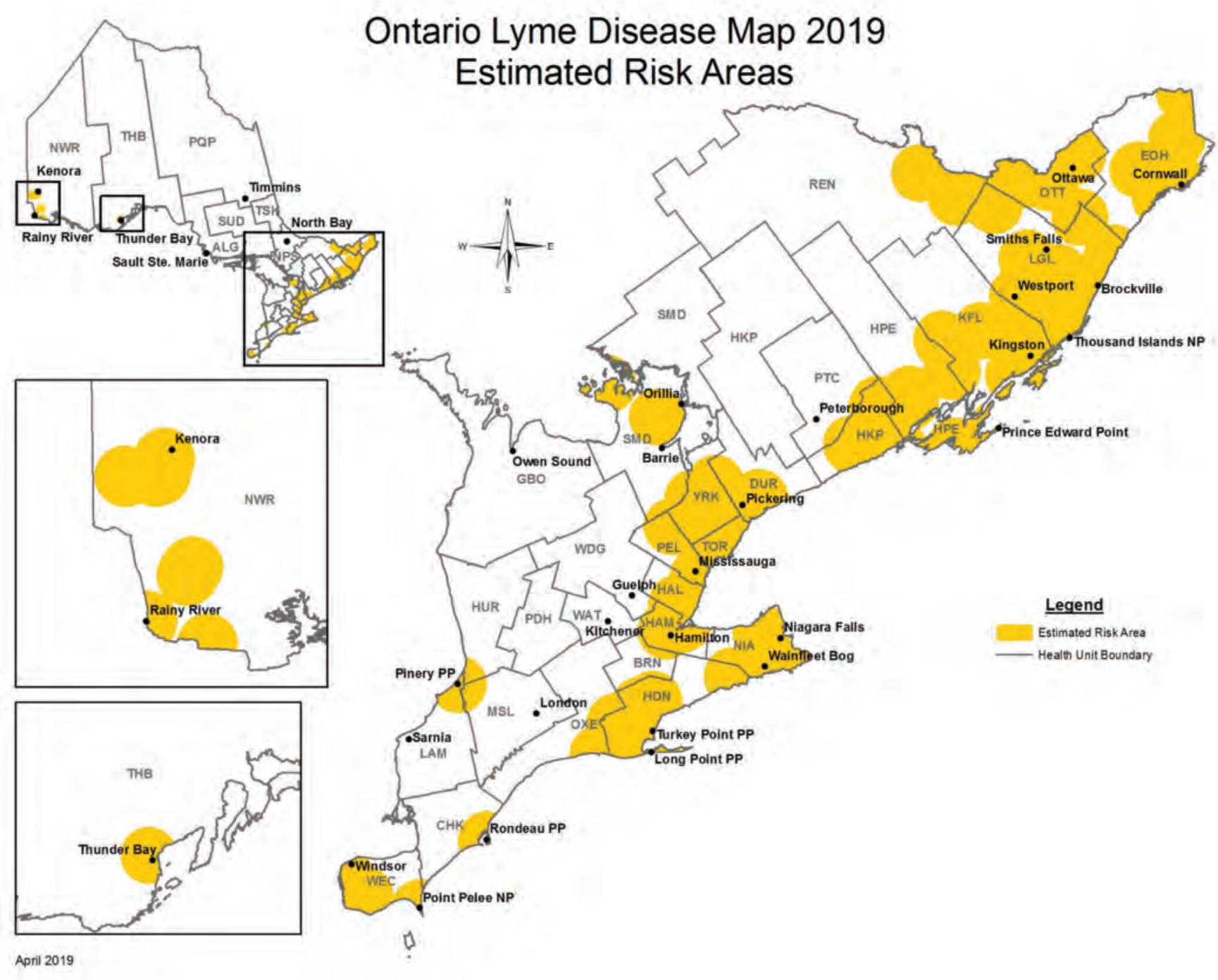

Figure 3: Risk map for Lyme disease. Estimated risk areas in Ontario (2019) (www.publichealthontario.ca/-/media/documents/lyme-disease-risk -area-map-2019). Published with permission of the Government of Ontario (Public Health Ontario).

encephalitis (3.7\%) were both uncommon. ${ }^{4}$ In a Norwegian study, neuroborreliosis more commonly presented with headache or meningismus than with cranial neuropathy. ${ }^{10} \mathrm{~A}$ review of clinical manifestations of Lyme disease in Ontario confirmed the unusual nature of this case. Late disseminated Lyme disease was most likely to present in May through September (81\%) and less than $3 \%$ of all cases of Lyme disease (erythema migrans, early disseminated or late disseminated) presented in December. ${ }^{11}$

Lyme disease is diagnosed based on clinical findings and supporting laboratory investigations. Erythema migrans, the earliest manifestation of Lyme disease, requires no laboratory confirmation and should be treated immediately with oral antibiotics. Early disseminated and late disseminated Lyme disease should be considered in endemic areas when patients present with compatible symptoms. Laboratory confirmation by 2-tiered Lyme serology is required. ${ }^{2}$ If results from serology testing are nonreactive and Lyme disease is still clinically suspected, then serology testing must be repeated 4-6 weeks later. Nonstandard testing is highly discouraged because of the high rate of false-positive results.
Oral doxycycline, amoxicillin or cefuroxime axetil are the antibiotics of choice for children with Lyme disease of almost any stage. Doxycycline can be used in all age groups for courses up to 10 days. ${ }^{11}$ For the treatment of Lyme meningitis, meningoencephalitis and carditis, intravenous ceftriaxone is recommended at presentation, but, after the patient improves, the antibiotic course may be completed orally. ${ }^{2,3}$

The keys to the diagnosis of neuroborreliosis in our case were the patient lived in an area endemic for Lyme disease, the preceding febrile illness and the photographic evidence of multiple regions of erythema migrans. The untreated, early disseminated Lyme disease progressed to late neuroborreliosis.

Ixodes scapularis is migrating northward and physicians should be familiar with the presentation of Lyme disease across all stages. In particular, recognition and treatment of early disease prevents progression to late disease. In addition, infection by other tick-borne pathogens, including Powassan virus, Anaplasma phagocytophilum and Babesia species, should be considered in the appropriate clinical contexts. These infections are 
also likely to increase in incidence with the changing habitat of I. scapularis. Preventive measures must be stressed in all areas at risk of transmission of Lyme disease to decrease the human burden of disease and help protect patients.

\section{References}

1. Infectious disease trends in Ontario [map]. Toronto: Public Health Ontario; updated 2019 Nov. 25. Available: www.publichealthontario.ca/data-and-analysis/ infectious-disease/reportable-disease-trends-annually\#/34 (accessed 2020 May 7).

2. Sood SK. Lyme disease in children. Infect Dis Clin North Am 2015;29:281-94.

3. Kimberlin DW, Brady MT, Jackson MA, et al., editors. Red Book 2018: report of the Committee on Infectious Diseases. 31st ed. Itasca (IL): American Academy of Pediatrics; 2018:515-23.

4. Knudtzen FC, Andersen NS, Jensen TG, et al. Characteristics and clinical outcome of Lyme neuroborreliosis in a high endemic area, 1995-2014: a retrospective cohort study in Denmark. Clin Infect Dis 2017;65:1489-95.

5. Halperin JJ. Neuroborreliosis. J Neurol 2017;264:1292-7.

6. Lindland ES, Solheim AM, Andreassen S, et al. Imaging in Lyme neuroborreliosis. Insights Imaging 2018;9:833-44.

7. Erol I, Sayg 1 S, Alehan F. Acute cerebellar ataxia in a pediatric case of Lyme disease and a review of literature. Pediatr Neurol 2013;48:407-10.

8. Overby P, Kapklein M, Jacobson RI. Acute ataxia in children. Pediatr Rev 2019;40:332-43.

9. Södermark L, Sigurdsson V, Näs W, et al. Neuroborreliosis in Swedish children: a population-based study on incidence and clinical characteristics. Pediatr Infect Dis J 2017;36:1052-6.

10. Øymar K, Tveitnes D. Clinical characteristics of childhood Lyme neuroborreliosis in an endemic area of northern Europe. Scand J Infect Dis 2009;41:88-94.

11. Johnson KO, Nelder MP, Russell C, et al. Clinical manifestations of reported Lyme disease cases in Ontario, Canada: 2005-2014. PLoS One 2018;13:e0198509.

\section{Competing interests: None declared.}

This article has been peer reviewed.

The authors have obtained patient consent.

Affiliations: Departments of Pediatrics (Myette, Leifso) and Public Health (Webber, Mikhail), Queen's University at Kingston Health Sciences Centre, Kingston, Ont.

Contributors: All of the authors contributed substantially to the conception and design of this case report; the acquisition, analysis and interpretation of data; drafted the manuscript; revised it critically for important intellectual content; gave final approval of the version to be published and agreed to be accountable for all aspects of the work in ensuring that questions related to the accuracy and integrity of any part of the work are appropriately investigated and resolved.

Correspondence to: Kirk Leifso, kirk.leifso@kingstonhsc.ca

CMAJ invites submissions to "What is your call?" Clinical details (including images) are presented with a multiple-choice question about the diagnosis. The answer and a brief discussion of the condition follow. We specifically invite submissions illustrating common or important radiographic and electrocardiographic diagnoses of appeal to a general audience. We require authors to obtain consent from the patient for publication of his or her story. Submit manuscripts online at http://mc.manuscriptcentral.com/cmaj 